\title{
Development of Ice Load Generation Module to Evaluate Station-Keeping Performance for Arctic Floating Structures in Time Domain
}

\author{
Hyun Hwa Kang®1, Dae-Soo Lee®1, Ji-Su Lim®1, Seung Jae Lee ${ }^{\circledR 2}$, \\ Jinho Jang ${ }^{\oplus^{3}}$, Kwang Hyo Jung ${ }^{\circledR 4}$ and Jaeyong Lee $\oplus^{5}$ \\ ${ }^{1}$ Graduate Student, Division of Naval Architecture and Ocean Systems Engineering, Korea Maritime and Ocean University, Busan, Korea \\ ${ }^{2}$ Professor, Division of Naval Architecture and Ocean Systems Engineering, Korea Maritime and Ocean University, Busan, Korea \\ ${ }^{3}$ Head of Ice-covered Waters Engineering Research Center, Division of Advanced Ship Research, KRISO, Daejeon, Korea \\ ${ }^{4}$ Associate Professor, Department of Naval Architecture and Ocean Engineering, Pusan National University, Busan, Korea \\ ${ }^{5}$ Associate Professor, Department of Naval Architecture and Ocean Engineering, Dong-eui University, Busan, Korea
}

KEY WORDS: Dynamic positioning in ice, Time domain simulation, Station keeping performance evaluation, Arctic floating structures, Statistical ice load generation

\begin{abstract}
To assess the station-keeping performance of floating structures in the Arctic region, the ice load should be considered along with other environmental loads induced by waves, wind, and currents. However, present methods for performance evaluation in the time domain are not effective in terms of time and cost. An ice load generation module is proposed based on the experimental data measured at the KRISO ice model basin. The developed module was applied to a time domain simulation. Using the results of a captive model test conducted in multiple directions, the statistical characteristics of ice loads were analyzed and processed so that an ice load corresponding to an arbitrary angle of the structure could be generated. The developed module is connected to commercial dynamic analysis software (OrcaFlex) as an external force input. Station-keeping simulation in the time domain was conducted for the same floating structure used in the model test. The mooring system was modeled and included to reflect the designed operation scenario. Simulation results show the effectiveness of the proposed ice generation module and its application to station-keeping performance evaluation. Considering the generated ice load, the designed structure can maintain a heading angle relative to ice up to $4^{\circ}$. Station-keeping performance is enhanced as the heading angle conforms to the drift direction. It is expected that the developed module will be used as a platform to verify station-keeping algorithms for Arctic floating structures with a dynamic positioning system.
\end{abstract}

\section{Introduction}

Despite the continued trend of low oil prices in recent times, the development of resources in the Arctic region is expected to continue, with Norway, the United States of America, and Russia at the forefront (Morgunova, 2020). In the polar regions, areas that can be developed have expanded because of global warming. Environmental conditions in the Arctic must be considered for the structures used to develop resources in these regions. Fixed structures are installed in shallow sea waters, while floating structures are considered first for deep-sea regions.

In general, the position of the floating structure is maintained using a mooring system. However, a dynamic positioning system (DPS) is sometimes used as an auxiliary system to cope with ice loads, which are one of the characteristics of the polar regions (Lee et al., 2019).

The DPS uses various kinds of thrusters to keep the position of a vessel or an offshore structure within the acceptable range. To do so, the DPS calculates the force required to return the floater from its altered position (caused by the external environmental forces) to its original position and generates the required force using the propulsion system. In the Arctic region, DP-assisted mooring systems are used for the extreme environment. A mooring system handles station-keeping functions for normal ocean environmental loads. However, when abnormal conditions arise, the DPS alleviates the excessive tensile force acting on the mooring system. It also maintains the position of the riser on the bottom of the structure so that the riser angle is within the acceptable range.

Simulations in the time domain are needed to evaluate the

Received 27 August 2020, revised 7 October 2020, accepted 12 October 2020

Corresponding author Jaeyong Lee: +82-51-890-2596, jlee@deu.ac.kr

It is noted that this paper is revised edition based on proceedings of KAOST 2020 in Busan.

(c) 2020, The Korean Society of Ocean Engineers

This is an open access article distributed under the terms of the creative commons attribution non-commercial license (http://creativecommons.org/licenses/by-nc/4.0) which permits unrestricted non-commercial use, distribution, and reproduction in any medium, provided the original work is properly cited. 
station-keeping performances of floating structures and observe how the tensile force acting on the mooring line changes over time. Modeling the environmental load acting on the structure is important. However, it is an extremely difficult task to incorporate the ice loads in the polar region into the time-domain simulations.

When it comes to evaluating the performance of a structure with DPS in seas where ice loads exist, the best method to collect data is to use the test results of a real sea experiment. In 2004, as part of the 302 Arctic coring expedition of the International Ocean Drilling Program (IODP), one drillship performed its drilling operations while being assisted by two icebreakers and collected data on how difficult it was to maintain its position (Moran et al., 2006). However, such real sea operation is extremely expensive, and the ice condition cannot be controlled; hence, it is impossible to obtain data for various situations.

Tests performed in ice tanks can also generate good data for evaluating the performance (Jenssen et al., 2009). Representative examples of such tests are the drillship-related experiments carried out as part of the Dynamic Positioning in Ice Condition (DYPIC) project, an international joint research project (Jenssen et al., 2012; Kerkeni et al., 2014), and the model tests performed by the National Research Council (NRC) of Canada (Wang et al., 2016; Islam et al., 2018). However, such ice tank tests are also costly, and there are limitations in simulating the actual conditions in these tests. For most ice tanks where the tests are performed, there is no equipment to reflect other environmental loads, such as wind, currents, and waves, in the test.

Studies are ongoing to perform simulations on the interactions between the ice and structures, considering the limitations mentioned above. Related to findiing an empirical formula, Kim et al. (2018a) proposed a method for extending the application of the existing model for level ice to pack ice. Furthermore, the relationship between the size of the broken ice floes and the resistance value was proposed (Jeong et al., 2018). Methods using numerical analysis techniques to analyze the behavior of the ice where ice floes exist mostly utilize the discrete-element method. This method models and interprets each particle as a discrete object for the finite-element method that uses differential equations of dynamic variables for a continuum. The discrete-element method was first proposed by Cundall and Strack (1979) and Walton (1982), and it was later applied to the ice-related field by Løset (1994) and others. Afterward, ArcISo (Arctic Integrated Solution), a spin-off company based on the Sustainable Arctic Marine and Coastal Technology (SAMCoT) of the Norwegian University of Science and Technology (NTNU), has made simulations of icestructure interactions, station keeping of floating structures, and navigation in icy sea waters possible through the SAMS (Simulator for Arctic Marine Structures) product (Lubbad et al., 2018a; Lubbad et al., 2018b; Raza et al., 2019).

Existing ice-structure interaction analysis methods consume too much time. To remedy this issue, Daley et al. $(2012,2014)$ developed graphics processing unit (GPU)-event mechanics (GEM). GEM uses a parallel structure GPU with excellent floating-point calculation performance to perform numerical computations. In general, the direction of ice drift and the current direction are set to match for these analysis software tools. Moreover, there is a limitation of not factoring in other ocean environmental loads, such as waves. To reflect the wave conditions, methods utilizing computational fluid dynamics have been proposed; however, considering such factors as analysis duration, there are limitations in incorporating various station-keeping equipment or applying changes to the algorithm. Therefore, the analysis methods mentioned above cannot set sufficient conditions to evaluate in the time domain the station-keeping performance of floating structures where ice loads exist.

To factor in combined environmental loads, including ice loads, the use of an existing commercial software for floating body motion analysis to assess the station-keeping performance in icy sea waters could provide a solution. For this purpose, a separate module must be developed to generate ice loads and reflect the ice loads in the motion analysis. Utilizing GEM and the mean value of the ice loads obtained from a tank experiment result, Kim et al. (2018b) proposed an ice load generation method using the spectral values of the variable components. However, the ice loads were measured only at a certain angle. Hence, this method cannot reflect changes to the ice loads based on the variation of the heading angle.

In this study, the aim was to identify the basic characteristics of the motion of a floater in ice condition through statistical processing based on the experimental data of ice loads measured at various angles. A separate ice load generation module was designed and implemented to reflect partially the statistical characteristics of experimental data using OrcaFlex, a general commercial floating body motion analysis software package. This setup made it possible to assess the station-keeping performance of Arctic floating structures for combined environmental loads and was applied to the evaluation of the heading-angle-keeping performance.

\section{Measurement of Ice Load in an Ice Tank Test and Post-processing of the Data}

\subsection{Experimental Setup and Conditions}

The floating structure used in this study is an Arctic floating production storage and offloading (FPSO) unit, and its length, breadth, and draft are 244, 57, and $18.6 \mathrm{~m}$, respectively. Fig. 1 shows the overall shape of the hull and the environment of the test in progress using a model with a scale ratio of 1:40. The model name assigned for the model test by Korea Research Institute of Ships and Ocean Engineering (KRISO) is KS1801. Table 1 shows a comparison between the detailed specifications of the model vessel built according to the scale ratio and the actual sizes.

For the resistance experiment for measuring the ice load, sensor values for calibration are measured at the zero section located at one end of the ice tank, as shown in Fig. 2. Afterward, the model vessel enters the ice region at a constant speed. Once the entire model vessel has entered the ice region, the vessel is in the measurement section, where data are measured stably. The data measured in this section are 
used as the resistance value due to ice.

To obtain data, the load cells were installed at the center of the model vessel. Once the vessel was secured to restrict its six-degreeof-freedom movements, the vessel was towed to pass through the ice region. Values measured by the sensors were processed by the hull-mounted coordinate system. The ice tank dimension at KRISO was $32 \mathrm{~m} \times 35 \mathrm{~m}$, and the tank was divided into sections so tests could be run multiple times. The shape of the ice floe was made irregular, and the ice concentration was set at $80 \%$. To convert ice in a real sea, which is $1.4 \mathrm{~m}$ thick and has a characteristic length of $12 \mathrm{~m}$, to the model scale, the actual size of the ice was divided by the scale of 40 to calculate the size of the ice used in the experiment. This result is shown in Table 2. The drift speed was $1.0 \mathrm{kt}(=0.5144 \mathrm{~m} / \mathrm{s})$, and it was divided by $\sqrt{40}$ to derive the towing speed $(0.081 \mathrm{~m} / \mathrm{s})$ in the experiment. The heading angle in the direction of the movement ranged from $-40^{\circ}$ to $40^{\circ}$ in intervals of $10^{\circ}$. Hence, the experiment was conducted for these nine intervals, and Fig. 3 shows the example of the measured values in time series, where the heading angle was set to $0^{\circ}$.
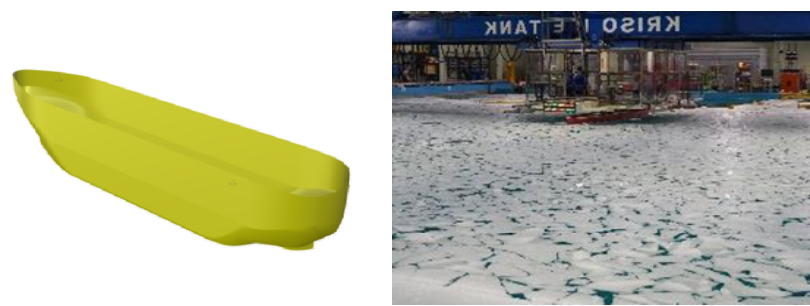

Fig. 1 Hull shape of the Arctic FPSO used in the experiment and simulation and overall environment of the model test in progress

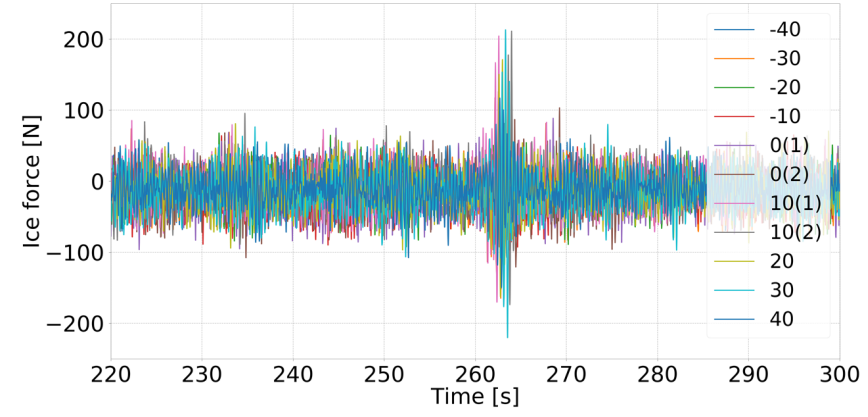

(a) $F_{x}$
Table 1 Principal particulars of the designed floater

\begin{tabular}{ccc}
\hline Description & Full scale & Model scale \\
\hline Length between perpendiculars (m) & 244 & 6.1 \\
Breath (m) & 50 & 1.25 \\
Draft (m) & 18.6 & 0.465 \\
Displacement $\left(\mathrm{m}^{3}\right)$ & 163,215 & 2.555 \\
Vertical center of gravity (m) & 19.5 & 0.4875 \\
\hline
\end{tabular}

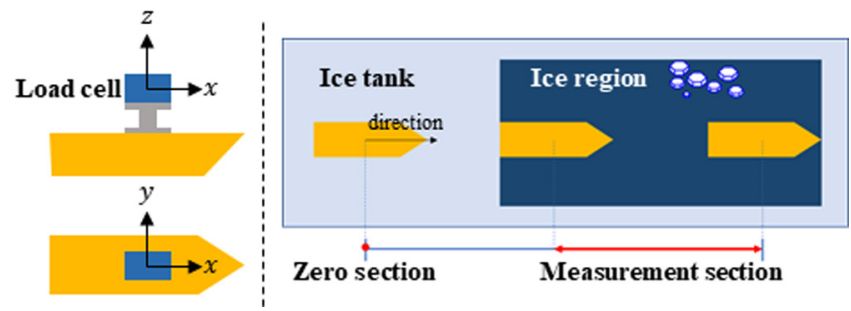

Fig. 2 Moving test vessel from the starting position (zero section) to the measurement area where ice floes are ready, and the coordinate system used in the measurement and data process

Table 2 Similitude of the ice condition

\begin{tabular}{ccc}
\hline Characteristics & Full scale & Model scale \\
\hline Ice thickness $(\mathrm{m})$ & 1.4 & 0.035 \\
Characteristic length for ice floes $(\mathrm{m})$ & 12 & 0.3 \\
Ice drift speed $(\mathrm{m} / \mathrm{s})$ & 0.514 & 0.081 \\
Ice concentration & \multicolumn{2}{c}{$8 / 10$} \\
Shape of ice floes & \multicolumn{2}{c}{ Irregular shapes } \\
\hline
\end{tabular}

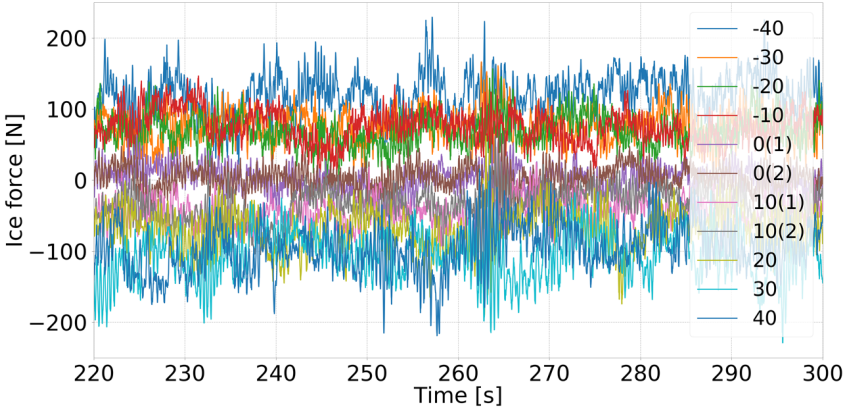

(b) $F_{y}$

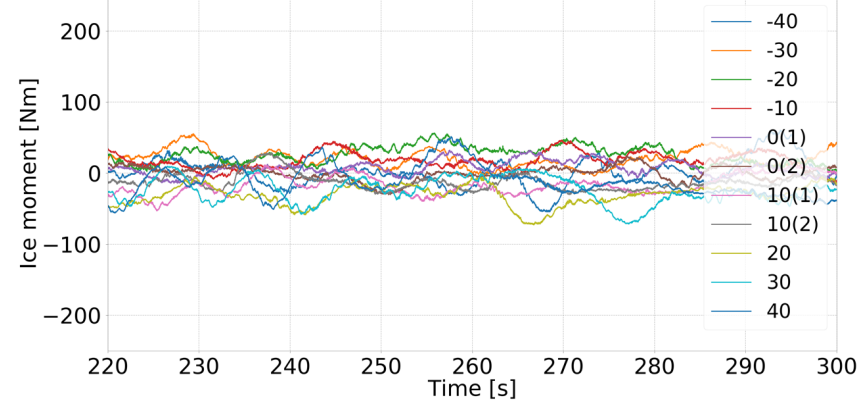

(c) $M_{z}$

Fig. 3 Time histories of $F_{x}, F_{y}$, and $M_{z}$ for the incident angle of $0^{\circ}$ from the model test 


\subsection{Post Processing of the Measured Data}

The data were measured every $10 \mathrm{~ms}$. To identify the statistical characteristics of the measured values for $F_{x}, F_{y}$, and $M_{z}$, each dataset was divided into 292 intervals using its minimum and maximum values as the reference. A histogram was drawn based on the ratio of each interval. Fig. 4 shows the measurement data for the heading angle of $0^{\circ}$. For comparison, the kernel density estimation, which estimates the density of the histogram, is represented by a red line, and a blue line represents the normal distribution graph based on the mean and standard deviation of the measured data.

A quantile-quantile plot (QQplot) was constructed to verify the normality shown from the appearance of the data, and QQplot examples are shown in Fig. 5. The QQplot is a method that plots the quantiles of a standard normal distribution and the quantiles of the corresponding distribution on the $\mathrm{x}, \mathrm{y}$-coordinate plane and graphically verifies two probability distributions. If the data shown in blue line up with a red line (representing the normal distribution) within the Z-score range of the standard normal distribution, the normality is verified.

The X-axis shows the Z-score of the QQplot graph for $F_{x}$. When the QQplot graph is viewed from the $\mathrm{x}$-axis perspective, the two distributions seem to align between 0 and \pm 2.5 , but the data and the red line show a discrepancy beyond this range. The histogram appears to follow the normal distribution, but there is a small difference between the data and the normal distribution curve as it gets closer to the extreme values. For $F_{y}$, the data and the red line agree reasonably well between 0 and \pm 3 , so it can be considered that the data possess normality. However, the $M_{z}$ graph shows some discrepancies.

To verify the normal distribution of the measured data quantitatively, the Kolmogorov-Smirnov test was performed. For 11 experimental sets, the sample distribution was set up for $33 F_{x}, F_{y}$, and $M_{z}$ component data. The normal distribution utilizing the mean value and the standard deviation of each set of data was used as the assumed distribution. The normality test was performed based on the $5 \% \mathrm{p}$-value, and the results have been marked by $\mathrm{P}$ (pass) and F (fail), as shown in Table 3.

Contrary to the predictions based on the form analysis of the measured data, the normality test results verified that the normal distribution was not followed except for some data sets related to $F_{y}$. Even when the log-normal distribution and other distributions were applied to the measured data, as was done by Zvyagin and Sazonov

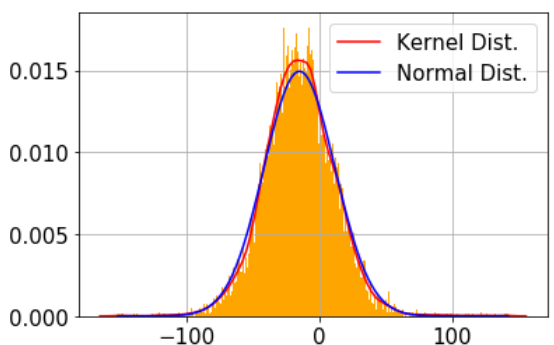

(a) $F_{x}$

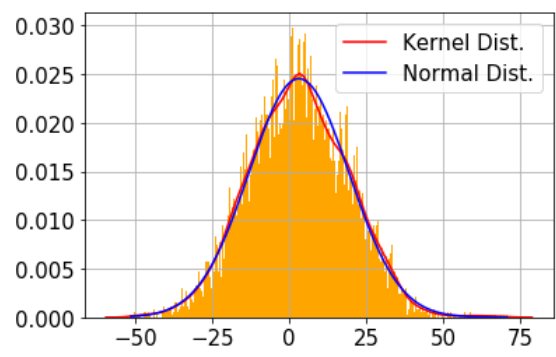

(b) $F_{y}$

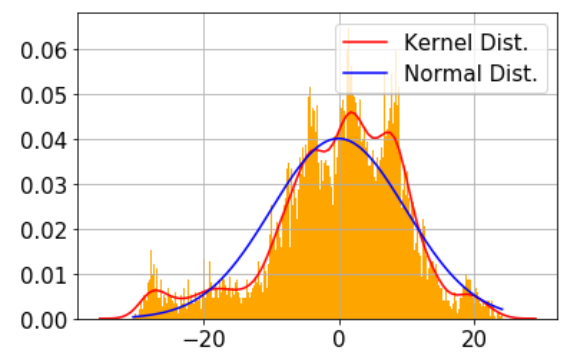

(c) $M_{z}$

Fig. 4 Histograms of $F_{x}, F_{y}$, and $M_{z}$ for the incident angle of $0^{\circ}$

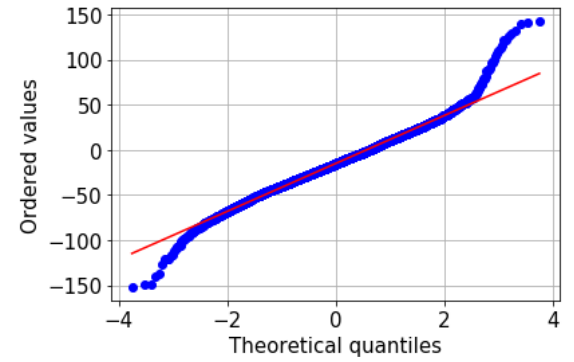

(a) $F_{x}$

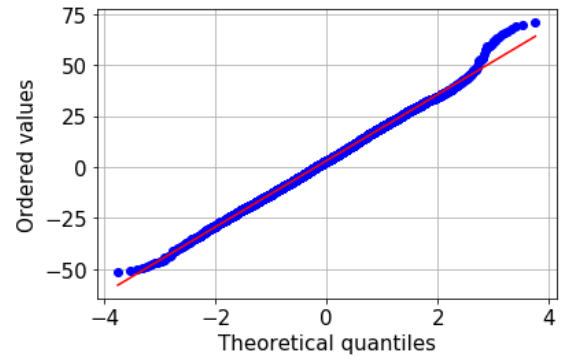

(b) $F_{y}$

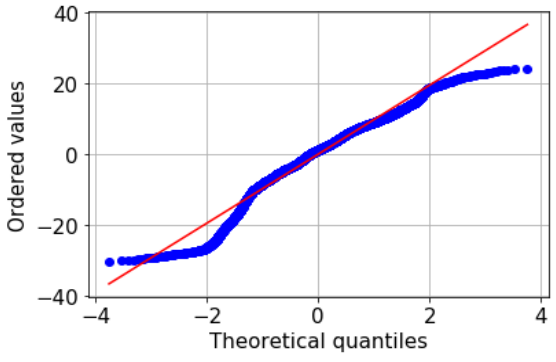

(c) $M_{z}$

Fig. 5 QQplots of $F_{x}, F_{y}$, and $M_{z}$ for the incident angle of $0^{\circ}$

Table 3 Results of Kolmogorov-Smirnov normality tests

\begin{tabular}{|c|c|c|c|c|c|c|c|c|c|c|c|c|}
\hline & & -40 & -30 & -20 & -10 & $0(1)$ & $0(2)$ & $10(1)$ & $10(2)$ & 20 & 30 & 40 \\
\hline \multirow{2}{*}{$F_{x}$} & p-value & 0.028 & 0.014 & $7.00 \mathrm{E}-04$ & 0.011 & $3.00 \mathrm{E}-05$ & $2.00 \mathrm{E}-03$ & $2.00 \mathrm{E}-08$ & $3.00 \mathrm{E}-09$ & $6.00 \mathrm{E}-07$ & 2.00E-08 & $6.00 \mathrm{E}-07$ \\
\hline & Pass/Fail & $\mathrm{F}$ & $\mathrm{F}$ & $\mathrm{F}$ & $\mathrm{F}$ & $\mathrm{F}$ & $\mathrm{F}$ & $\mathrm{F}$ & $\mathrm{F}$ & F & $\mathrm{F}$ & $\mathrm{F}$ \\
\hline \multirow{2}{*}{$F_{y}$} & p-value & 0.114 & 0.132 & $2.00 \mathrm{E}-08$ & 0.158 & 4.00E-03 & 0.35 & 0.97 & 4.00E-09 & $7.00 \mathrm{E}-10$ & $5.00 \mathrm{E}-05$ & $8.00 \mathrm{E}-03$ \\
\hline & Pass/Fail & $\mathrm{P}$ & $\mathrm{P}$ & $\mathrm{F}$ & $\mathrm{P}$ & $\mathrm{F}$ & $\mathrm{P}$ & $\mathrm{P}$ & $\mathrm{F}$ & F & $\mathrm{F}$ & $\mathrm{F}$ \\
\hline \multirow{2}{*}{$M_{z}$} & p-value & $2.00 \mathrm{E}-36$ & $1.00 \mathrm{E}-15$ & $5.00 \mathrm{E}-49$ & $2.00 \mathrm{E}-05$ & $3.00 \mathrm{E}-22$ & $7.00 \mathrm{E}-25$ & $6.00 \mathrm{E}-54$ & $3.00 \mathrm{E}-82$ & $6.00 \mathrm{E}-30$ & $2.00 \mathrm{E}-32$ & $1.00 \mathrm{E}-68$ \\
\hline & Pass/Fail & $\mathrm{F}$ & F & F & F & F & $\mathrm{F}$ & F & F & F & F & F \\
\hline
\end{tabular}


(2014), the results showed that the assumed distribution was not satisfied. This result shows the difficulty of applying statistical methods to ice load generation and the differences in methods measuring the ice resistance. It was determined that $F_{x}$ tends to deviate from the normal distribution at either extreme value of the QQ plot graph because of outliers measured at certain intervals (260-270 s). Here, $F_{y}$ shows a tendency to form a normal distribution based on the incident angle, and $M_{z}$ seems to be affected by the characteristics of the sensor, which performs calculations based on the measured values of $F_{x}$ and $F_{y}$. However, there is still a need to develop an ice load generation module. This module is required for running simulations in the time domain. The statistical processing method can be developed at a later time. Furthermore, meaningful results can be achieved in determining the design parameters if the simulation is run repeatedly. Ice load generation logic that assumes a normal distribution using the mean and standard deviation of the measured values was applied in this study.

\section{Ice Load Generation in Time Domain Simulation}

\subsection{Process to Generate Random Value to an Arbitrary Heading Angle}

The mean and standard deviation values of the measured data for each angle are shown in Table 4. As shown in Fig. 6, curve fitting was performed after plotting the mean values on the graph. The formulas for mean value interpolation of $F_{x}, F_{y}$, and $M_{z}$ for arbitrary head angles $(\psi)$ are shown in Eq. (1).

$$
\begin{aligned}
& F_{x}=-0.0657 \psi-11.139 \\
& F_{y}=0.0013 \psi^{3}-0.0013 \psi^{2}-4.5748 \psi+5.8412 \\
& M_{z}=0.0009 \psi^{3}-0.0044 \psi^{2}-1.6498 \psi+1.4689
\end{aligned}
$$

Here, $F_{x}$ is expressed in a linear function, $F_{y}$ and $M_{z}$ and are expressed in a cubic function. When used in simulations, the Froude number is applied according to the full-scale vessel, the average value of $F_{x}$ and $F_{y}$ is multiplied by $\lambda^{3}$, and the standard deviation function
Table 4 Mean and standard deviation values of the measured data

\begin{tabular}{ccccccc}
\hline \multirow{2}{*}{$\begin{array}{c}\text { Angle } \\
(\mathrm{deg})\end{array}$} & $F_{x}$ & $F_{y}$ & $M_{z}$ & $F_{x}$ & $F_{y}$ & $M_{z}$ \\
& $(\mathrm{~N})$ & $(\mathrm{N})$ & $(\mathrm{Nm})$ & $(\mathrm{N})$ & $(\mathrm{N})$ & $(\mathrm{Nm})$ \\
\hline-40 & -8.802 & 120.469 & 1.265 & 21.167 & 28.615 & 20.557 \\
-30 & -14.236 & 75.561 & 20.466 & 22.028 & 22.557 & 12.486 \\
-20 & -13.537 & 69.616 & 25.512 & 24.545 & 21.779 & 12.426 \\
-10 & -15.336 & 76.145 & 17.586 & 25.819 & 22.304 & 12.03 \\
$0(1)$ & -17.188 & 2.005 & 7.148 & 26.376 & 17.723 & 10.143 \\
$0(2)$ & -15.112 & 3.102 & -0.046 & 26.701 & 16.259 & 9.934 \\
$10(1)$ & -7.276 & -44.398 & -16.219 & 27.253 & 19.165 & 14.036 \\
$10(2)$ & -7.304 & -36.329 & -12.59 & 27.03 & 22.357 & 11.484 \\
20 & -13.455 & -69.629 & -30.641 & 26.828 & 28.193 & 14.222 \\
30 & -15.655 & -106.159 & -23.915 & 29.385 & 32.913 & 18.683 \\
40 & -11.538 & -95.908 & -11.428 & 24.576 & 33.22 & 22.276 \\
\hline
\end{tabular}

of $M_{z}$ is multiplied by.

The same method was used for the standard deviation, and curve fitting was performed to obtain the standard deviation for an arbitrary angle. Unlike the mean value, two separate trend lines were used to perform interpolation, one from $-40^{\circ}$ to $0^{\circ}$ and another from $0^{\circ}$ to $40^{\circ}$, to ensure that the trend line is as close to all the measured data points as possible. In other words, $F_{x}, F_{y}$, and $M_{z}$ each has interpolation functions for two standard deviations, with $0^{\circ}$ being the reference point. The results are shown in Eq. (2). The values of the interpolation function for the standard deviation were also derived based on the measured values from the model test. In the full-scale vessel simulation, the horizontal force $\left(F_{x}, F_{y}\right)$ and moment $\left(M_{z}\right)$ are multiplied by the third power and the fourth power of the scale ratio, respectively.

$$
\begin{gathered}
F_{x}=\left\{\begin{array}{lll}
-0.0002 \psi^{3}-0.0118 \psi^{2}-0.0491 \psi+26.538 & \text { if } & \psi \geq 0 \\
-0.0005 \psi^{3}-0.0253 \psi^{2}-0.2215 \psi+26.538 & \text { if } & \psi<0
\end{array}\right. \\
F_{y}=\left\{\begin{array}{lll}
-0.0009 \psi^{3}-0.0538 \psi^{2}-0.9575 \psi+17 & \text { if } & \psi \geq 0 \\
-0.0007 \psi^{3}-0.0340 \psi^{2}-0.1314 \psi-17 & \text { if } & \psi<0
\end{array}\right. \\
M_{z}=\left\{\begin{array}{lll}
-0.0008 \psi^{3}-0.0389 \psi^{2}-0.5504 \psi+10.038 & \text { if } & \psi \geq 0 \\
-0.0031 \psi^{2}-0.1821 \psi+26.538 & \text { if } & \psi<0
\end{array}\right.
\end{gathered}
$$

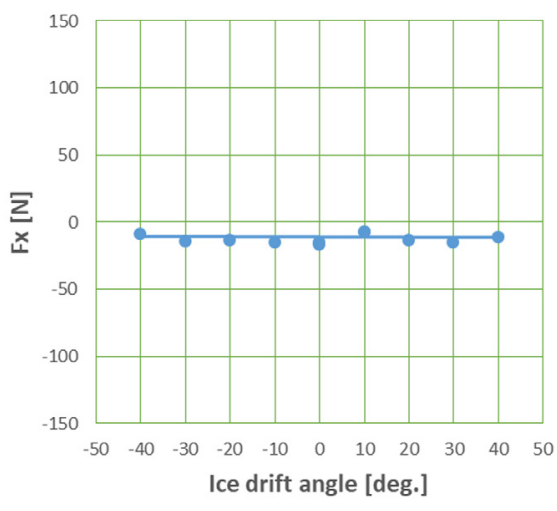

(a) Curve fitting for $F_{x}$

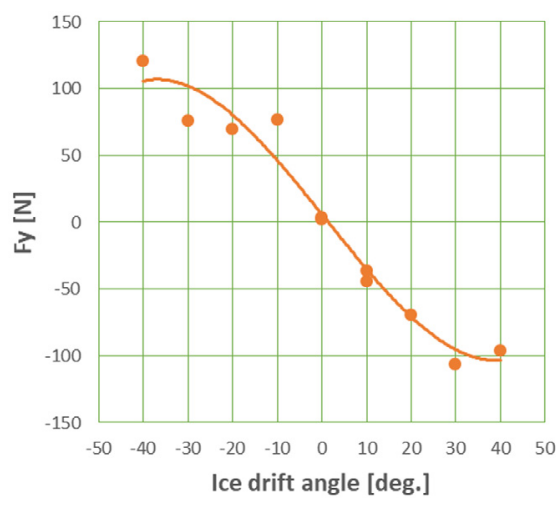

(b) Curve fitting for $F_{y}$

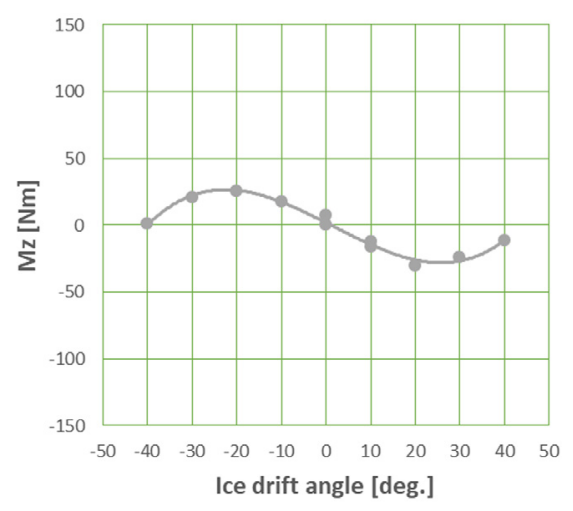

(c) Curve fitting for $M_{z}$

Fig. 6 Curve fittings of mean values in Table 4 for each direction 
The measured values in the experiment are the resistance values obtained when the model vessel was towed in the ice tank; hence, the ice load and the current force corresponding to the speed of the vessel are included in these values. Therefore, the current force needs to be subtracted from the measured values to extract the pure ice load. This process is necessary to isolate the ice load from the direction upon which the current force is acting. Generally, ice is set to drift in the direction of the current, but the movement of the ice can be affected by the wind. Therefore, it is better to set the directions of the ice drift and current differently. However, realistically, it is difficult to conduct additional towing experiments to obtain the value of the current force. Hence, the current force was calculated after securing the structure at a fixed position in OrcaFlex and assuming the current flows in a constant direction.

The vessel was secured to restrict its six-degree-of-freedom movements, and the relative angle between the current and the structure was set from $-40^{\circ}$ to $40^{\circ}$ in intervals of $5^{\circ}$. Afterward, the sea current environment was configured, and data were obtained. The data values are recorded in Table 5. Based on these data, curve fitting was performed to derive the interpolation function for calculating the current force for each angle, similar to the mean and standard deviation of the ice load.

Table 5 Current load corresponding to heading angles

\begin{tabular}{cccc}
\hline Heading angle & $F_{C, x}$ & $F_{C, y}$ & $M_{C, z}$ \\
\hline-40 & -31.388 & -185.868 & -3604.123 \\
-30 & -34.465 & -141.555 & -2853.264 \\
-20 & -35.696 & -97.858 & -2102.405 \\
-10 & -35.696 & -51.083 & -1201.374 \\
0 & -33.85 & 6.155 & 0 \\
10 & -35.696 & 51.083 & 1201.374 \\
20 & -35.696 & 97.858 & 2102.405 \\
30 & -34.465 & 141.555 & 2853.264 \\
40 & -31.388 & 185.868 & 3604.123 \\
\hline
\end{tabular}

\subsection{Module for Ice Load Generation}

In the Arctic region, the heading angle of the floating structure keeps changing according to changes in the direction of the main environmental external force. If the heading angle is altered because of the environmental load while ice is drifting toward the structure, the ice load value acting upon it should also change. Furthermore, depending on the size and shape of the ice on the sea where the structure is operating, ice loads of varying sizes and directions are continuously applied, even if the heading angle remains constant. Therefore, to reflect how changes in the heading angle of the structure affect the ice load in the simulation, one must be able to generate the ice load applied to the vessel at the specified angle.

Fig. 7 shows a diagram of the process for how the ice load module generates ice load when performing dynamic analysis in the time domain. OrcaFlex, which is used for the dynamic analysis, is

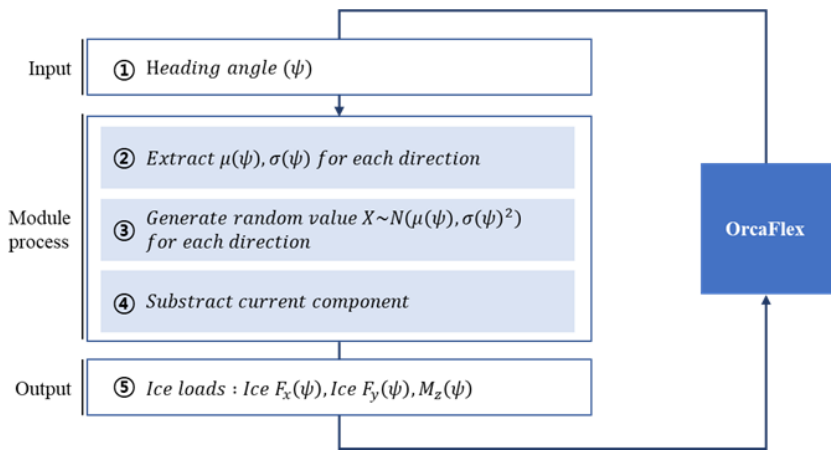

Fig. 7 Ice load generation process inside of the module

configured to perform the analysis in intervals of $0.1 \mathrm{~s}$. Because the ice load generation process is repeated throughout the entire simulation duration, ice loads are generated every $0.1 \mathrm{~s}$ and are applied in the analysis.

(1) The analysis software sends the current heading angle information of the floating structure to the ice load generation module as an input.

(2) The mean $(\mu(\psi))$ and standard deviation $(\sigma(\psi))$ of the $F_{x}, F_{y}$, and $M_{z}$ component measurement data are calculated for the input heading angle. The interpolation formula described in Eqs. (1) and (2) of Section 3.1 are used for this calculation.

(3) The probability density function for a typical normal distribution is defined as shown in Eq. (3).

$$
f(x)=\frac{1}{\sqrt{2 \pi} \sigma} e^{-\frac{1}{2}\left(\frac{x-\mu}{\sigma}\right)^{2}}
$$

Here, a normal distribution is assumed for the mean $(\mu(\psi))$ and standard deviation $(\sigma(\psi))$ values for the corresponding heading angle, and a random number $\left(X \sim N\left(\mu(\psi), \sigma(\phi)^{2}\right)\right)$ is generated from the probability density function as an output.

(4) The current force for the input heading angle is subtracted, and a final ice load value is generated as an output.

(5) The process is completed by applying the ice load generated by the ice load generation module to the center of gravity of the structure in the dynamic analysis software.

\section{Simulation Results}

\subsection{Setup for Simulation}

The analysis process performed by the analysis software (OrcaFlex) and two external modules is shown in Fig. 8. To perform the analysis of the floating structure, which factors in the DP in icy sea waters, the analysis software sends the information each module needs, such as the current position and speed of the floating object and the status of the mooring system. When the heading angle information is sent to the ice load module, the ice load generation process earlier explained is performed. Afterward, the ice load applied to the floating object for the corresponding heading angle is generated as output and sent to the 


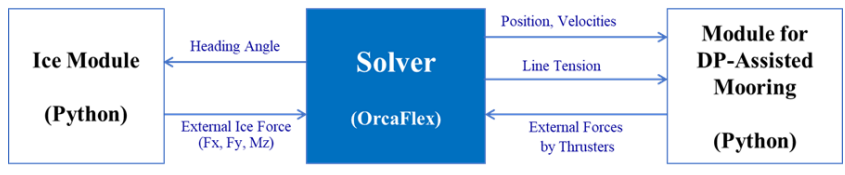

Fig. 8. Simulator configuration with external modules for ice load generation and DP force generation

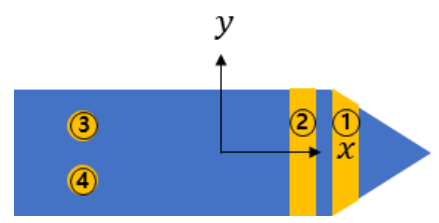

Fig. 9 Arrangement of DP thrusters

analysis software. After receiving information, such as the position and speed of the vessel and the tension on the mooring line, the DP module computes and returns the required thrust for each thruster to maintain the desired heading angle and position. The two modules were developed using Python. The ice load and thrust values returned from the modules are integrated with the environmental load, vessel motion, and mooring line information within OrcaFlex to assess the station-keeping performance.

Fig. 9 shows the arrangement of the DPS installed on the floating object subject to analysis. Two tunnel thrusters are located at the bow of the vessel, and two Azipod thrusters are located at the stern of the vessel to assist the mooring system. Considering the characteristics of the DP-assisted mooring, the arrangement was designed to focus on maintaining direction rather than station-keeping performance. Table 6 shows the thrust capacity and position of each thruster. The target position of the DPS was the initial coordinates of the vessel, and the target heading angle was set to have a constant value along the direction in which the ice load is acting.

The mooring system used for station keeping was designed using OrcaFlex, and its arrangement is shown in Fig. 10. It is an internal turret mooring system and consists of four bundles. Each bundle consists of four mooring ropes in the form of chain-wire-chain. The water depth of the sea area where the mooring system is expected to be installed is $200 \mathrm{~m}$. The footprint radius was set at 5.0, which is five times the depth of the water. The minimum breaking load (MBL) of the chain was designed at $26,952 \mathrm{kN}$.

The Barents Sea in the Arctic region was selected as the area where the station-keeping simulation would be performed. Based on the maritime data measured in the selected sea area, conditions were

Table 6 Specifications and coordinates of the thrusters

\begin{tabular}{cccccc}
\hline Turret No. & $\begin{array}{c}\text { Type of } \\
\text { thruster }\end{array}$ & Thrust $(\mathrm{kN})$ & $x$ & $y$ & $z$ \\
\hline 1 & Tunnel & 330 & 91 & 0 & 0 \\
2 & Tunnel & 330 & 86 & 0 & 0 \\
3 & Azipod & 1600 & -113 & 6.5 & 0 \\
4 & Azipod & 1600 & -113 & -6.5 & 0 \\
\hline
\end{tabular}

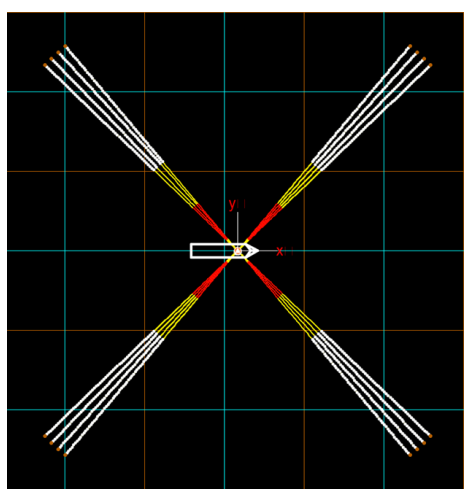

Fig. 10. Configuration of the mooring system for the floater

Table 7 Environmental conditions for the stationkeeping simulation

\begin{tabular}{ccccccccc}
\hline & \multicolumn{3}{c}{ Direction (deg) } & \multicolumn{5}{c}{ Magnitude } \\
\cline { 2 - 8 } Case & \multicolumn{3}{c}{ Ice } & Wave & Wind Current & $\begin{array}{c}\text { Wave } \\
H_{s}(\mathrm{~m})\end{array} T_{p}(\mathrm{~s})$ & $\begin{array}{r}\text { Wind } \\
(\mathrm{m} / \mathrm{s})\end{array}$ & $\begin{array}{c}\text { Current } \\
(\mathrm{m} / \mathrm{s})\end{array}$ \\
\hline 1 & 165 & 165 & 165 & 165 & & & & \\
2 & 180 & 180 & 150 & 135 & 10.3 & 13.71 & 31.86 & 0.78 \\
3 & 145 & 180 & 150 & 135 & & & & \\
\hline
\end{tabular}

determined by applying a return period of one year for the waves, 10 years for the current, and 100 years for the wind. This setting was chosen because large waves are not formed in areas covered with ice, while the wind still causes a huge impact. Applying the same ice load for the station-keeping analysis under an ice-free condition created a harsh condition. It was verified that station keeping was impossible under such a condition. Table 7 shows the magnitude of each marine environment and the direction in which it is acting. The direction in which environmental conditions of wave, wind, and current are acting was configured based on the DNVGL-OS-E301 standards. Case 1 is a collinear condition where the environmental loads act in the direction that is $15^{\circ}$ relative to the direction towards the bow of the vessel. Cases 2 and 3 are noncollinear conditions. Here, the waves are acting in the direction toward the bow, while the wind and current are acting in the directions that are $30^{\circ}$ and $45^{\circ}$ relative to the direction of the waves, respectively. Meanwhile, the direction in which the ice load acts generally follows the direction of the current. However, because it is affected by the wind, there are no definitive rules for the direction of the ice load. Hence, the direction of the ice load was set to match the direction of other environmental loads for the collinear condition. In Case 2, it was configured to align with the incident angle of the waves. For Case 3, the direction of the ice load was set to be halfway between the current and the wind directions to consider the interactions between the current and the wind.

\subsection{Validation Test for the Ice Load Generated by the Developed Module}

The station-keeping simulation was performed using the ice load module, considering the ice load based on the changes in the heading angle. The heading angle was maintained within $10^{\circ}$ of the target 


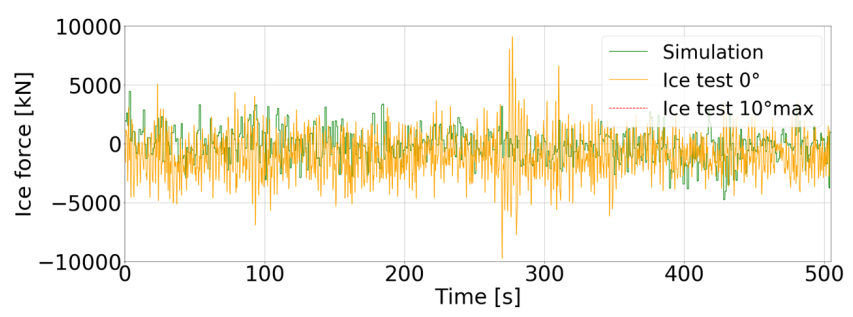

(a)

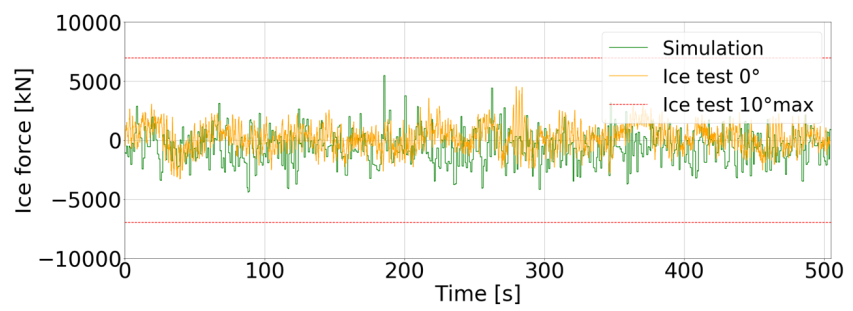

(b)

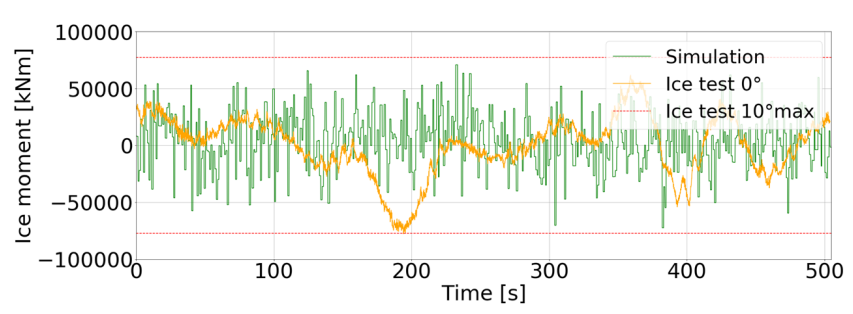

(c)

Fig. 11 Comparison between ice loads from the model test and the simulation

heading angle. Hence, the ice load data generated in time series were examined to determine whether they lie within the maximum values of the measured data in the towing experiments with incident angles of $0^{\circ}$ and $10^{\circ}$. The comparison results are shown in Fig. 11. The entire set of simulation data spans over $12,000 \mathrm{~s}$. However, only the simulation data from the first $500 \mathrm{~s}$ were represented in the graph to compare the data values directly.

The ice load data generated by the module are represented by a green line, while the measured values from the experiments are represented by a yellow line. The red lines above and below the ice load data represent the maximum measured values when the incident angle is $10^{\circ}$. (a) The $F_{x}$ graph has the highest qualitative similarity between the values generated by the module and the experimental measurement values. (b) The $F_{y}$ graph shows slight differences, but the generated values and the measured values lie within the maximum measurement values from the $10^{\circ}$ towing experiment. (c) The $M_{z}$ comparison graph has the largest difference from a normal distribution, and the generated values and the measured values are slightly different. However, the random values are still generated normally within the maximum values.

The ice load, along with other environmental loads, acts on the structure. Thus, the magnitudes of the environmental loads recorded in the simulation were compared to check the proportion of the ice load to the total load, and the comparison graphs are shown in Fig. 12. Graphs (a), (b), and (c) are plots of the entire environmental load by

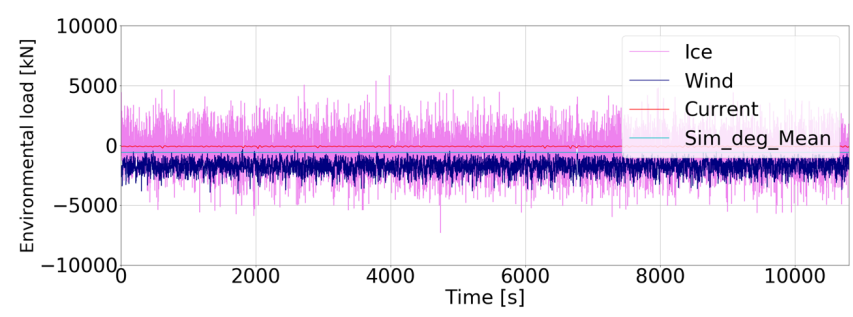

(a)

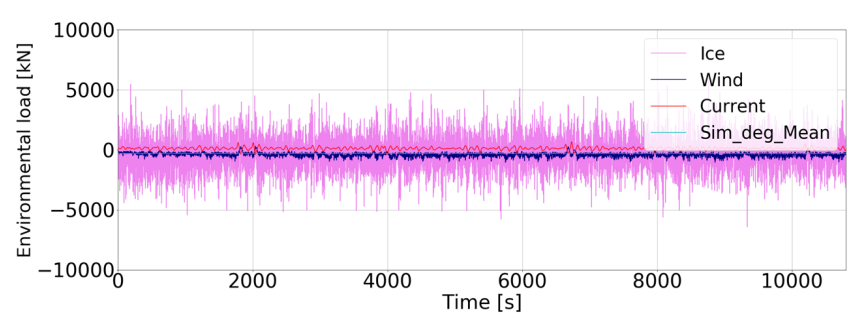

(b)

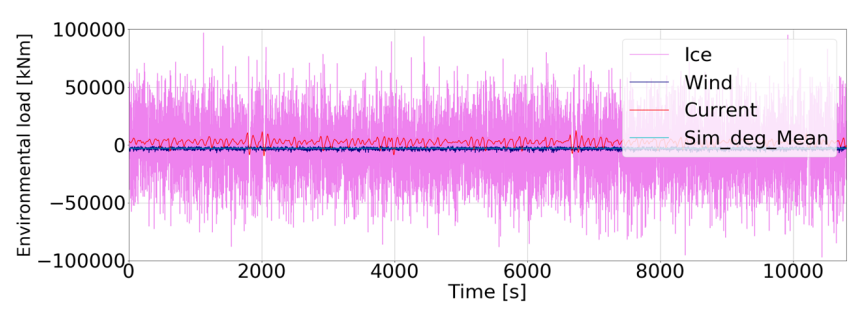

(c)

Fig. 12 Comparison of magnitude of ice load with other environmental loads

each factor for the x-axis, $\mathrm{y}$-axis directional loads, and z-axis moment of the structure. The variation was approximately $10^{\circ}$ from the target heading angle at each time point on the graph. Therefore, graph (a), which compares the loads acting on the x-axis, confirmed that the ice load is larger than other environmental loads. Furthermore, graphs (b) and (c) show that the magnitude of the wind has the greatest value. However, the variation in the heading angle is not significant; hence, the $y$-axis directional load and z-axis directional moment caused by waves are greater than those induced by the ice load, wind, and current.

\subsection{Derivation of Limit Status of DP Heading Control}

To verify that the generated ice load acts on the floating object properly and derive the limitations of the DP performance based on the direction in which the ice load acts, a position control test and heading angle control test were performed on the DPS without mooring lines

\section{Test 1}

Maintain initial heading angle $\mathrm{n}^{\circ}$

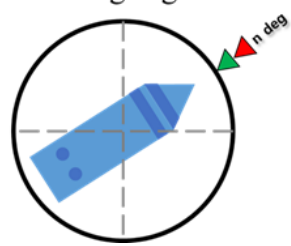

\section{Test 2}

Rotation from the initial heading angle $n^{\circ}$ to $0^{\circ}$

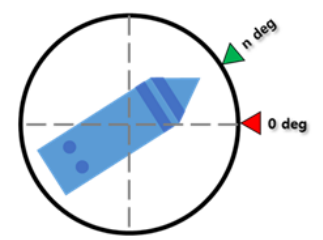

Initial angle Target angle

Fig. 13 Setting for the performance test of the DP heading control 


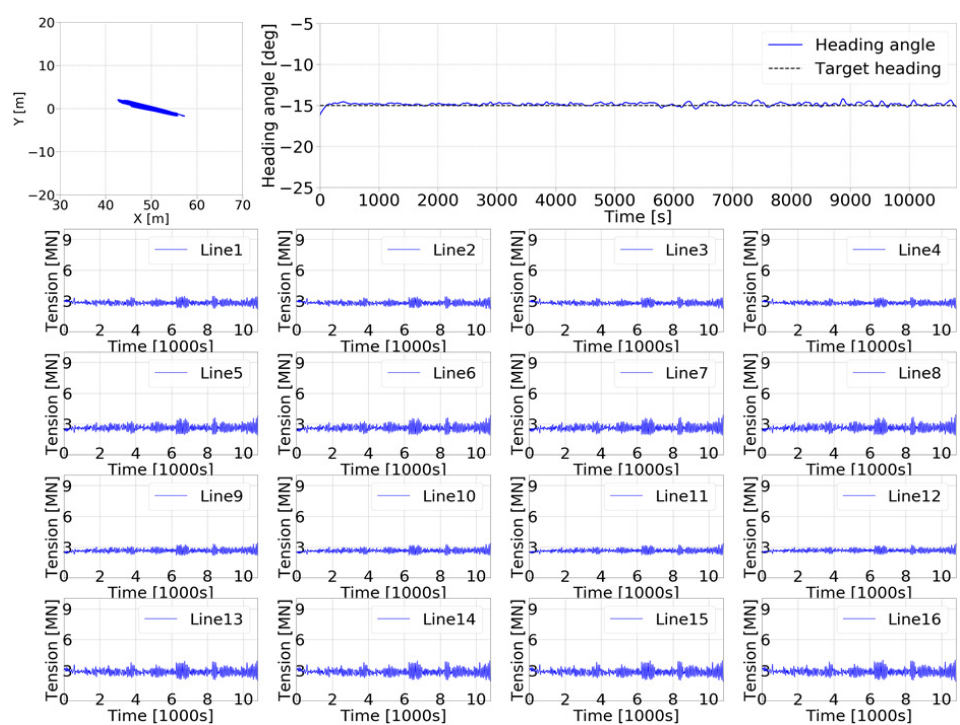

(a) Case 1

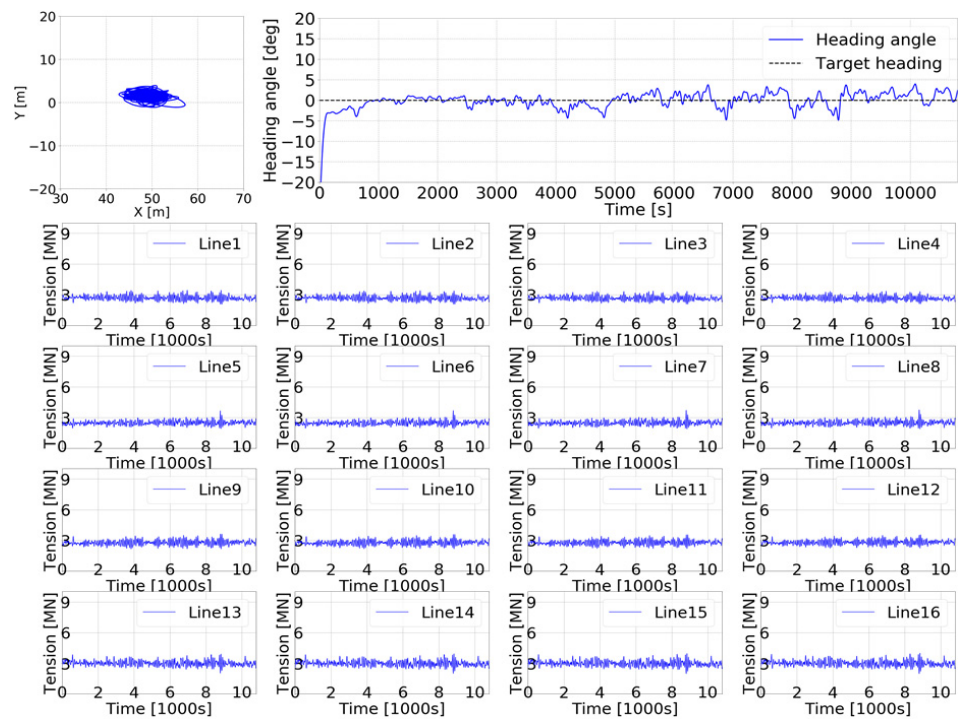

(b) Case 2

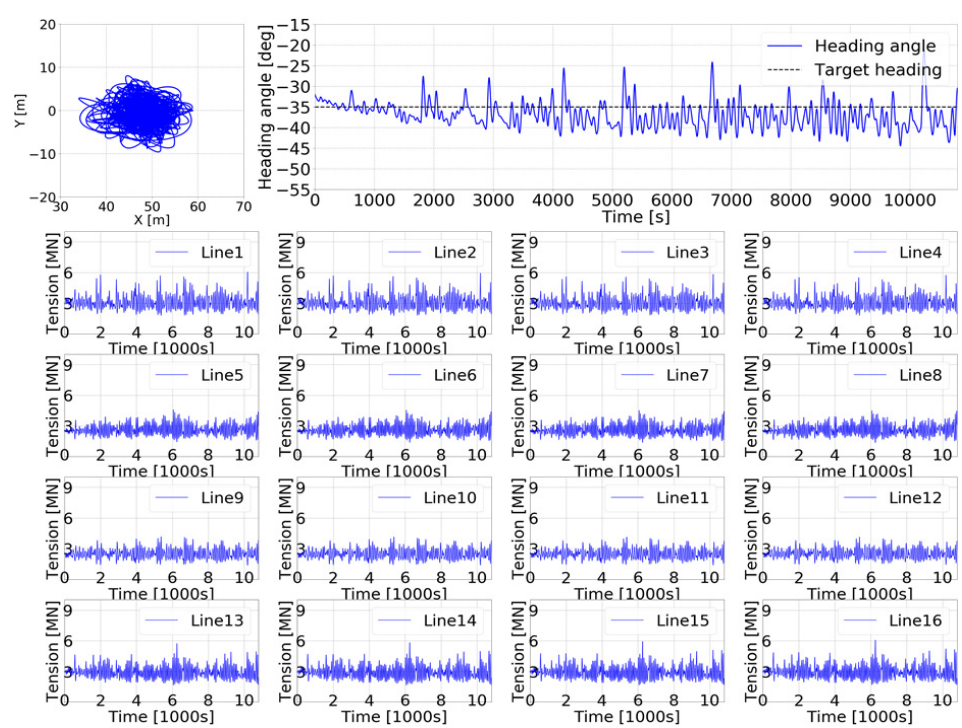

(c) Case 3

Fig. 14 Simulation results of designed DP-assisted mooring system for the cases in Table 7 
under the environmental conditions, considering only the ice load. Test 1, shown in Fig. 13, involved continuously maintaining the heading angle, which was initially set to an arbitrary value. In Test 2 , the maximum angle that satisfies the station-keeping performance was verified when the DPS was rotated from the initial heading angle, which was set arbitrarily to the target heading angle selected based on the direction of the ice load.

In Test 1 , the station-keeping and direction control performances were satisfactory from $0^{\circ}$ to $4^{\circ}$. However, the DPS could not be controlled at angles greater than or equal to $5^{\circ}$ because of the excessive environmental loads. Due to the thrust capacity of the thrusters at the stern of the vessel, based on their location, creates limitations in maintaining the position and controlling the direction simultaneously. In Test 2, station keeping and direction control were made possible by rotating in the direction in which the ice load is acting, up to $17^{\circ}$, to minimize the ice load. However, the control performance was lost at or above $18^{\circ}$ because the environmental loads could not be withstood when rotating toward the target heading angle. Through this test, it was verified that the generated ice load is properly acting on the structure.

\subsection{Evaluation of Stationkeeping Performance}

An evaluation must be performed to determine whether the station-keeping performance of the structure is suitable for the environment of the sea area when the ice load is acting on the structure in icy sea waters. The position and heading angle information and the mooring line tension information based on the analysis results of the DP-assisted mooring system, considering the environmental loads, are shown in Fig. 14. The environmental conditions for Cases 1-3 have been explained earlier, and Figs. 14(a)-(c), respectively, are the graphs of the results for these cases. The magnitude of the environmental loads is the smallest for the collinear condition described in Case 1. When Cases 2 and 3 are compared, both having a noncollinear condition, the overall environmental load of Case 2 is smaller than that of Case 3. In Case 2, the ice load acts in the direction toward the bow of the vessel, while the direction of the wind and the current direction have a contained angle in Case 3. All analysis results show that the position of the structure was kept within the target radius of $25 \mathrm{~m}$. Moreover, it was verified that the radius tends to fluctuate in proportion to the magnitude of the environmental loads based on the target heading angle. The data for the mooring line tension graph contain values ranging from 0 to $10,000 \mathrm{kN}$. These values are small compared with $16,171.2 \mathrm{kN}$, which is equivalent to $60 \%$ of the MBL and is a tension requirement for survival conditions. In other words, the position requirements and mooring line tension requirements were met for all conditions. Thus, it can be concluded that station-keeping performance has been satisfied from the perspective of the station keeping of the structure and the tensile force of the mooring lines.

To verify the DPS auxiliary performance, the results of the DP-assisted mooring system in Case 3, which has a relatively harsher condition, were compared with the results of a stand-alone mooring system under the same environmental loads. The graphs in Fig. 15 show the comparison of the position and heading angle data and the mooring line tension data between the DP-assisted mooring system and the stand-alone mooring system.

The red line represents the stand-alone mooring system results, and the blue line represents the results of the DP-assisted mooring system. The simulation results showed that both systems satisfy the target radius for station keeping. In addition, the tension values of mooring lines fall within the acceptable range, within $60 \%$ of the MBL, and meet the criteria. However, compared with the DP-assisted mooring system, the stand-alone mooring system drifted toward the upper-left region and came close to the target radius of $25 \mathrm{~m}$ in the case of station keeping. Furthermore, the tension graphs in the fourth row represent the data for tension acting on the fourth bundle (mooring lines 13-16)
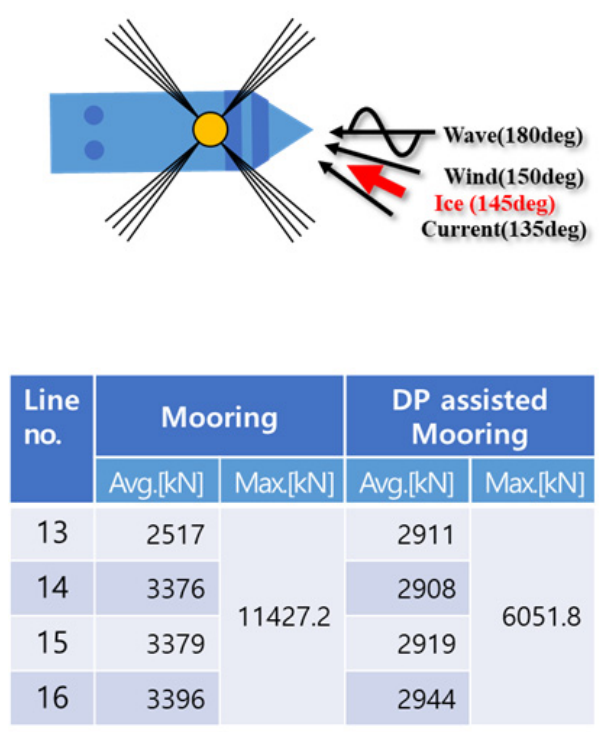

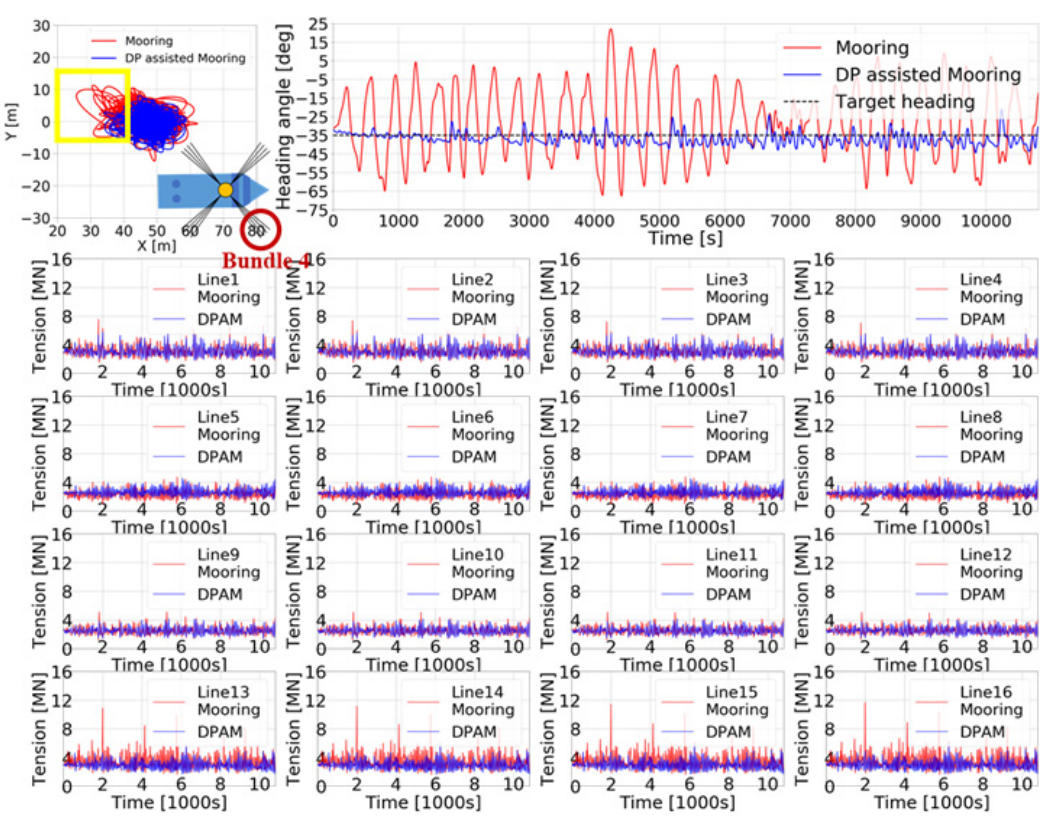

Fig. 15 Comparison of mooring line tensions between DP-assisted mooring (DPAM) and stand-alone mooring systems 
as the vessel drifted toward the upper-left region. The fourth bundle is located in the lower-right part of the vessel. The graphs verified that the stand-alone mooring system tension values are greater than the tension values for the DP-assisted mooring system.

The average tension for the fourth bundle of the stand-alone mooring system is $3,167 \mathrm{kN}$, and there is a large difference in average tension between mooring line 13 and mooring lines 14-16. However, the average tension for the bundles of the DP-assisted mooring system is $2,920.5 \mathrm{kN}$, and the average tension of each mooring line is similar. The average tension reduction caused by the DPS is $200 \mathrm{kN}$, and the difference in maximum tension between the two systems is 5,375.4 $\mathrm{kN}$. Hence, the tension reduction effect can be verified.

\section{Conclusions}

To perform a simulation of the DP-assisted mooring system in the time domain based on the results of the experiments conducted in the ice tank, an ice load generation module was developed, and its process was established. An interpolation function was generated based on the mean and standard deviation of the measured data, and the mean and standard deviation values for an arbitrary heading angle were set. An arbitrary random number was generated by assuming a normal distribution to establish a process for generating ice loads in a particular time and heading angle.

Using a module developed in Python, commercial dynamic analysis software, OrcaFlex, was configured such that the ice load can be input as an additional load. A simulation was performed to assess the station-keeping performance of the floating structure in the polar region, which was designed for combined environmental loads, including the ice load. The results of the simulation are summarized as follows.

(1) Although the simulated ice loads lacked statistical consistency with the experimental data, their validity was verified by creating ice loads that share some of the statistical characteristics and applying them to the simulation in the time domain. Although random variables were generated by assuming a normal distribution in this study, other distributions, such as a log-normal distribution, can be easily applied. Because the direction angle of the structure kept changing in the simulation, it is difficult to make a direct comparison between the simulation data and the values measured in the experiment while maintaining a particular angle. However, the analysis of the mean and maximum values, one of the main factors that characterize the ice load, is deemed acceptable.

(2) Using the relative magnitude of the ice load and the DPS, it was found that the limit for maintaining the heading angle is approximately $4^{\circ}$. For the floating structure applied in the simulation, there were limitations in maintaining the position and controlling the heading angle simultaneously because the difference in thrust value between the thrusters installed at the bow and stern was significant.

(3) Efforts were made to control the heading angle so it would match the ice load. As a result, the heading angle and the ice load could be matched, even when the contained angle was at $17^{\circ}$. The overall load acting on the structure is reduced by rotating the heading angle in the direction where the load is exerting the greatest force. As a result, it is possible to control the station keeping. This result, along with the previous simulation results, can be used as a reference for setting the acceptable heading angle in the DP-assisted mooring system.

(4) Simulations were performed under a collinear condition, as well as under two different noncollinear conditions where the direction in which the ice load acts was different. The results showed that the station-keeping systems satisfied the performance requirements of the design phase. Because the mooring system is designed rather conservatively, the DPS did not seem to contribute to the station-keeping function. However, in a noncollinear condition, the difference in maximum tension between the stand-alone mooring system and the DP-assisted mooring system was 5,375 kN. Hence, the tension reduction effect of the DPS was shown. This result could be the basic data for redesigning a mooring system.

Based on this study, further simulations are planned to effectively operate the designed structure in harsh maritime environments. The sensor system will be replaced in the planned experiments to measure the ice load more accurately. Moreover, the ice load generation module will be enhanced so that additional factors needed to generate the ice load in the time domain can be studied and incorporated. Currently, the target position and direction of the DPS are used by setting arbitrary constant values. In the future, its logic should be reconstructed to proactively contribute to the tension reduction of the mooring system.

\section{Acknowledgments}

This research was funded by Ministry of Trade, Industry \& Energy (MOTIE, Korea) under Industrial Technology Innovation Program No. 10063405, "Development of hull form of year-round floating type offshore structure based on the Arctic Ocean in ARC7 condition with dynamic positioning and mooring system," and Dong-eui University Grant (No. 202003500001).

\section{References}

Cundall P.A., \& Strack, O.D.L. (1979). A Discrete Numerical Model for Granular Assemblies, Géotechnique, 29(1), 47-65. https://doi.org/10.1680/geot.1979.29.1.47

Daley, C.G., Alawneh, S., Peters, D., Blades, G., \& Colbourne, B. (2014), Simulation of Managed Sea Ice Loads on a Floating Offshore Platform using GPU-event Mechanics. Proceedings of the International Conference and Exhibition on Performance of Ships and Structures in Ice, Banff, Canada.

Daley, C.G., Alawneh, S., Peters, D., Quinton, B.W.T., \& Colbourne, B. (2012). GPU Modeling of Ship Operations in Pack Ice. Proceedings of the International Conference and Exhibition on Performance of Ships and Structures in Ice, Banff, Canada. 
Islam M., Wang, J., Brown, J., Lau, M., Gash, R., Millan, D., \& Millan, J. (2018). Physical Model Testing for Supporting Ice Force Model Development of DP Vessels in Managed Ice. Proceedings of OTC Arctic Technology Conference, St. John's, Canada. https:// doi.org/10.4043/29157-MS

Jeong, S.-Y., Jang, J., Kim, C.-H., Yum, J.-G., \& Kang, K.-J. (2018). A Study of Ship Resistance Characteristics for Ice-strengthened Vessel by Broken Ice Channel Width and Size of Broken Ice Pieces. Journal of the Society of Naval Architects of Korea, 55(1), 22-27. https://doi.org/10.3744/SNAK.2018.55.1.22

Jenssen, N.A., Hals, T., Jochmann, A., Santo, X.D., Kerkeni, S., Doucy, O., ... \& Løset, S. (2012). DYPIC-A Multi-National R\&D Project on DP Technology in Ice. Proceedings of the Dynamic Positioning Conference, Houston, USA.

Jenssen, N.A., Muddesitti, S., Phillips, D., \& Backstrom, K. (2009). DP in Ice. Proceedings of the Dynamic Positioning Conference, Houston, USA.

Kerkeni, S., Santo, X.D., Doucy, O., Jochmann, P., Haase, A., Metrikin, I.A., ... \& Støle-Hentschel, S. (2014). DYPIC Project: Technological and Scientific Progress Opening New Perspectives. Proceedings of Arctic Technology Conference, Houston, USA.

Kim, H.S., Han, D., Lee, J.-B., \& Jeong, S.-Y. (2018a). An Estimation of Attainable Speed in Brash Ice using Empirical Formula. Journal of the Society of Naval Architects of Korea, 55(4), 313-320. https://doi.org/10.3744/SNAK.2018.55.4.313

Kim, Y.-S., Kim, J.-H., Kang, K.-J., Han, S., \& Kim, J. (2018b). Ice Load Generation in Time Domain Based on Ice Load Spectrum for Arctic Offshore Structures. Journal of Ocean Engineering and Techology, 32(6), 411-418. https://doi.org/10.26748/KSOE. 2018.32.6.411

Lee, J., Choi, S.-M., Lee, S.J., \& Jung, K.H. (2019). Tension Based Heading Control Strategy of the Arctic FPSO with DP Assisted Mooring System. Proceedings of the ASME 2019 38th International Conference on Ocean, Offshore and Arctic Engineering, Glasgow, UK.https://doi.org/10.1115/OMAE201996557

Løset, S. (1994). Discrete Element Modelling of a Broken Ice FieldPart I: Model Development. Cold Regions Science and Technology, 22(4), 339-347. https://doi.org/10.1016/0165-232X (94)90019-1

Lubbad, R., Løset, S., Lu, W., Tsarau, A., \& van den Berg, M. (2018a). An Overview of the Oden Arctic Technology Research Cruise 2015 (OATRC2015) and Numerical Simulations Performed with SAMS driven by Data Collected during the Cruise. Cold Regions
Science and Technology, 156, 1-22. https://doi.org/10.1016/ j.coldregions.2018.04.006

Lubbad, R., Løset, S., Lu, W., Tsarau, A., \& van den Berg, M. (2018b). Simulator for Arctic Marine Structures. Proceedings of the ASME $201837^{\text {th }}$ International Conference on Ocean, Offshore and Arctic Engineering, Madrid, Spain. https://doi.org/10.1115/OMAE 2018-78592

Moran, K., Backman, J., \& Farrel, J.W. (2006). Deepwater Drilling in the Arctic Ocean's Permanent Sea Ice, Proceedings of the Integrated Ocean Drilling Program, 302. https://doi.org/10.2204/ iodp.proc.302.106.2006

Morgunova, M. (2020). Why is Exploitation of Arctic Offshore Oil and Natural Gas Resources Ongoing? A Multi-level Perspective on the Cases of Norway and Russia. The Polar Journal, 10, 1-18. https://doi.org/10.1080/2154896X.2020.1757823

Raza, N., van der Berg, M., Lu, W., \& Lubbad R. (2019). Analysis of Oden Icebreaker Performance in Level Ice Using Simulator for Arctic Marine Structures (SAMS). Proceedings of the $25^{\text {th }}$ International Conference of Portand Ocean Engineering under Arctic Conditions, Delft, The Netherlands.

Walton, O.R. (1982) Explicit Particle Dynamics Model for Granular Materials, Proceedings of 4th International Conference on Numeriacal Methods in Geomechanics, Edmonton, Canada.

Wang, J., Sayeed, T., Millan, D., Gash, R., Islam M., \& Millan J. (2016). Ice Model Tests for Dynamic Positioning Vessel in Managed Ice. Proceedings of OTC Arctic Technology Conference, St. John's, Canada. https://doi.org/10.4043/27430-MS

Zvyagin, P., \& Sazonov, K. (2014). Analysis and Probailistic Modeling of the Stationary Ice Loads Stochastic Process with Lognormal Distribution. Proceedings of the ASME 2014 33rd International Conference on Ocean, Offshore and Arctic Engineering, San Francisco, USA. https://doi.org/10.1115/OMAE2014-24713

\section{Author ORCIDs}

Author name
Kang, Hyun Hwa
Lee, Dae-Soo
Im, Ji-Su
Lee, Seung Jae
Jang, Jinho
Jung, Kwang Hyo
Lee, Jaeyong

ORCID

0000-0003-3690-4776

0000-0003-1800-2277

0000-0003-2154-4296

0000-0001-8992-6915

0000-0001-7979-4314

0000-0002-8229-6655

0000-0002-4469-7765 